\title{
Energy Efficiency Ratio (EER) of Novel Air Conditioning System on LPG Fuelled Vehicle: A Lab-Scale Investigation
}

\author{
Muji Setiyo $^{1 *}$, Budi Waluyo ${ }^{1}$, Paolo Gobbato ${ }^{2}$ and Massimo Masi $^{3}$ \\ ${ }^{1}$ Department of Automotive Engineering, Universitas Muhammadiyah Magelang \\ Jl. Bambang Soegeng, Mertoyudan, Magelang 56172, Indonesia \\ "Email: setiyo.muji@ummgl.ac.id \\ Phone: +62293326945 \\ ${ }^{2}$ Veil Energy Srl, NOI Techpark, Bolzano, Italy \\ ${ }^{3}$ Department of Management and Engineering, University of Padova, Vicenza, Italy
}

\begin{abstract}
Alternative fuels have become an effective solution to reduce the impact of road transport on the environment. On the other hand, the growing uses of air-conditioning (AC) have contributed to worsening the fuel economy of passenger vehicles. Liquid petroleum gas (LPG), if injected in the gaseous phase to power SI engines, may allow reducing the fuel consumption due to $\mathrm{AC}$ devices through the recovery of cooling energy from the fuel systems. This paper presents lab-scale tests of an air conditioning system prototype for LPG-fuelled vehicles. The prototype has been assembled using standard vehicle components to quantify the cooling energy recoverable from the LPG evaporation before the fuel is injected into the engine intake manifold. Temperature and humidity of the air exiting the LPG evaporator are measured for fuel mass flow rates typical of light-duty vehicles. The energy efficiency ratio (EER) of the prototype achieves 2.72 when cooling power equals $1.2 \mathrm{~kW}$. Although the system tested needs improvements, the experimental data show that the cooling energy recovered by LPG evaporation can significantly reduce the power consumption of standard AC systems in passenger cars.
\end{abstract}

Keywords: LPG fuelled vehicle; LPG evaporation; vehicle air-conditioning; energy efficiency ratio.

\section{NOMENCLATURE}

$\begin{array}{ll}h & \text { air enthalpy of air } \\ \dot{m}_{a} & \text { air mass flow rate } \\ \dot{q}_{e v} & \text { cooling power } \\ w_{b} & \text { electric blower power }\end{array}$

\section{INTRODUCTION}

The first application of LPG-fuelled vehicle dates more than 100 years ago, but only in recent decades, LPG has become an actual substitute for gasoline in SI engines [1]. LPG has a high energy content per unit mass (about $46.23 \mathrm{MJ} / \mathrm{kg}$, a value slightly higher than gasoline), but a low energy content per unit volume (about $25.4 \mathrm{MJ} / \mathrm{m}^{3}$ at $101,300 \mathrm{~Pa}$ and $15^{\circ} \mathrm{C}$ ) [2]. Gasoline-designed engines modified to be LPG-fuelled with vapour phase LPG kits show a reduction in performance when gaseous LPG is injected into manifolds because the intake air displaced by fuel [3-6]. Masi \& Gobbato found that performance 
loss could also be caused by the evaporator device operation and tuning [3]. Indeed, improved power output (and emissions) of LPG-fuelled vehicles were obtained by Ceviz et al. [7] by controlling the temperature of LPG within the fuel rail, and by Cinar et al. [8] by proper management of injection duration and the application of modified valve lifter to improve volumetric efficiency.

The performance loss can be almost nullified compared to gasoline operation when vehicle use liquid phase direct injection [9]. This strategy is pursued in the fourth generation of converter kits, in which injection duration and ignition timing are controlling by engine control module (ECM) based on analogue and digital data from the engine sensors. However, to date, LPDI is still being developed due to many challenges in complex control systems and the selection of materials for injectors to be able at high temperatures [10-14].

Recently, Suyabodha [15] found that the LPG fuelling allows an energy saving equal to $1.16 \mathrm{MJ} / \mathrm{km}$ compared to RON 95 gasoline fuelling on the same car running conditions. This result agrees with the emission data presented by Norris [16]. These relevant advantages of LPG fuel against gasoline, which result from a Tank-To-Wheels (TTW) analysis, are less marked if a Well-To-Tank (WTT) analysis is accounted for. Edwards et al [17] show that in the overall energy and Green-House-Gas (GHG) balances (i.e., in a Well-To-Wheels analysis) the LPG-fuelled SI engine performs slightly better than the same engine run with gasoline, and place LPG as a valuable short-to-medium term alternative fuel to gasoline.

LPG-fuelled engines may provide a further benefit if the cooling effect produced by fuel evaporation is recovered. Price et al. [18] tested a Ford Focus equipped with a water-cooled LPG evaporator. The authors measured an engine coolant temperature drop equal to $6 \mathrm{~K}$ at the maximum engine power operation by the engine coolant flow rate of $0.1 \mathrm{~kg} / \mathrm{s}$ (i.e., at an LPG flow rate of about $6 \mathrm{~g} / \mathrm{s}$ ). In a previous work of the present authors, it was shown that the cooling effect could be smartly used to support the AC system of the passenger car [19]. The airflow, before entering the cabin, provides the necessary heat to evaporate the LPG that is going to the combustion chamber of SI engine. The LPG vaporization leads to a temperature and humidity reduction of the airflow at a low cost, essentially limited to the additional evaporator required by the modified fuel line, the fan needed to force the airflow across the evaporator, and the electrical power consumed by the fan.

The recovering of cooling power produced by the LPG evaporation may have a significant impact on fuel consumption. As it is known that the $400 \mathrm{~W}$ load on a conventional engine can save fuel around $0.4 \mathrm{~km} / 1$ and that the power absorbed by a standard vehicle air-conditioning compressor may achieve $3 \mathrm{~kW}$ when the cooling load equals $7 \mathrm{~kW}$ [20]. According to Benouali et al. [21], two experimental studies by National Renewable Energy Laboratory (NREL) and The French Environment and Energy Management Agency (ADEME) report that fuel consumption on SI engines increases by $35-38 \%$ during summer due to the AC system operation. In a similar study, Bharathan et al. [22] found that fuel waste due to the AC system load was around 20-25\%. More relevant increases are quoted in the literature when the vehicle operates at low engine speeds $[23,24]$.

From a general point of view, the fuel consumption due to the use AC systems in Europe was equal to $3.2 \%$ of total global fuel consumption [25], whereas Johnson [26] estimated that in 2002 the use of fuel for light-duty vehicles AC system in the US was equivalent to $6 \%$ of domestic petroleum consumption, or $10 \%$ of crude oil imports. These percentages must be contextualised in their time and cannot be considered a valid 
estimation of today's consumption. Nevertheless, they clearly state that any solution capable to limit/optimize the load of the usual air conditioning system could strongly affect the worldwide energy consumed by vehicles. In addition, it is worth noting that LPG has good properties as refrigerant fluid and its impact on the environment could be lower than conventional fluids used for vehicle AC, as shown in several studies [27-31].

This paper presents an experimental analysis of an LPG pressurereduction/evaporator system in which the cooling effect is used to reduce the temperature and the humidity of airflow. The experimental tests are performed on a lab-scale prototype assembled using stock components of a passenger car. Compared to the author's previous work [19], which is focused on Coefficient of Performance (COP), the present study extends the discussion on the behaviour of the pressure-reduction/evaporator system and reports the system performance in terms of Energy Efficiency Ratio (EER). The prototype is tested at six LPG mass flow rates that span the fuel consumption range of a light-duty vehicle.

\section{METHOD}

It is well-known that engines fuelled by LPG gaseous port injection need for a device that evaporates the LPG stored at liquid state in the tank and reduces its pressure before the fuel is injected into the engine intake manifold. Figure 1(a) shows the thermodynamic process occurring within this device. As reported in a previous study [19], this process can find the necessary heat to evaporate the LPG from the airflow required by the cabin $\mathrm{AC}$ system, as sketched in Figure 1(b). The devices are shown by capital letters B and C in the figure are the pressure control/reduction valve and evaporator, respectively, which must be added to the standard kit for LPG gas injection (marked with a capital letters D and $\mathrm{E}$ in the figure).
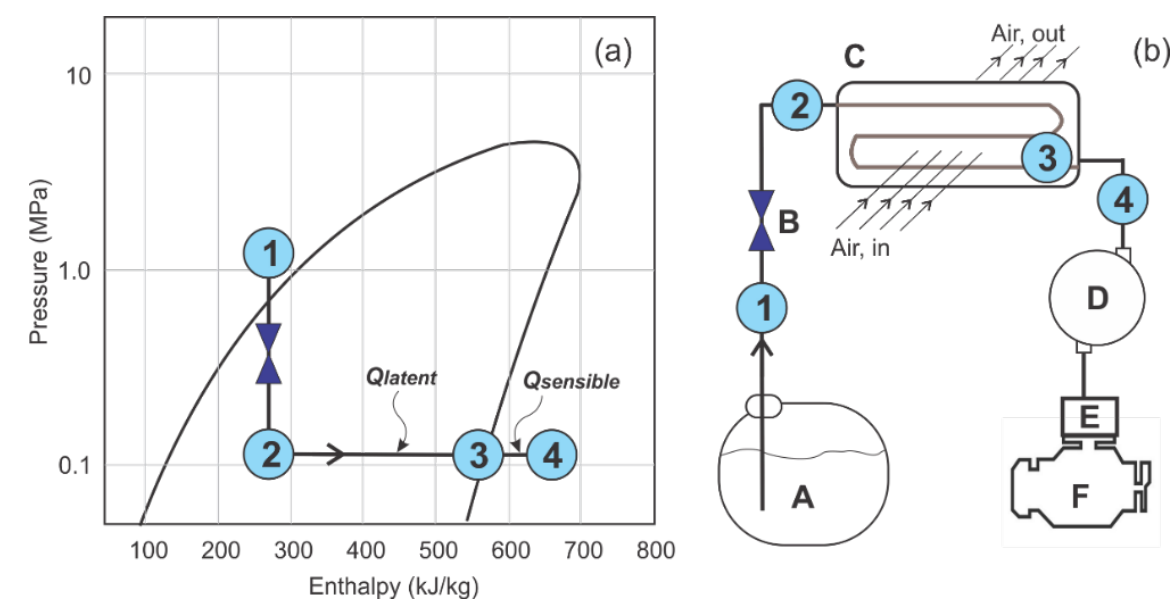

Figure 1. P-h diagram of the isenthalpic pressure reduction and evaporation process (a) and schematic of a $1 / 2$ cycle AC system based on LPG evaporation (b).

The system sketched in Figure 1(b) was assembled as shown in Figure 2. A 40 litres LPG tank (1) equipped with multiple valves and shut-off valve (2) was connected to the typical expansion valve (3) an evaporator (4), a centrifugal blower (7) to force the air across the evaporator, and other auxiliary equipment. Further details on the facility are available in the previous work [19]. Note that: the typical expansion valve (3) is made of nylon $(0.24 \mathrm{~W} / \mathrm{mK})$ to minimise heat losses; the evaporator (4) has been taken from a 
Peugeot 206 OEM air conditioning system because of its compact design and lowpressure drop; size of the blower and its rotational speed were selected based on maximum potential heat transfer. All the tests were performed at $380 \mathrm{~m}$ above sea level at the barometric pressure equal to $96.842 \mathrm{kPa}$.

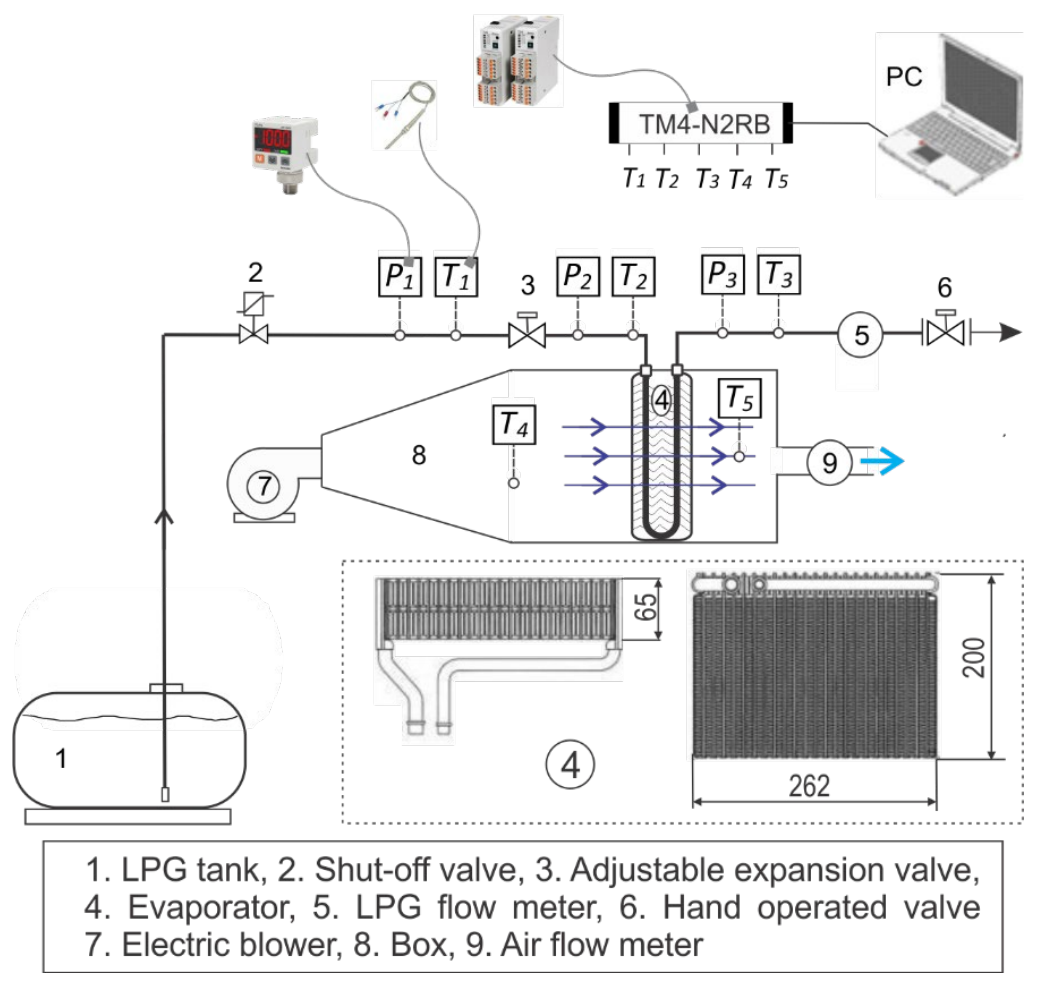

Figure 2. Schematic of the experimental facility (evaporator dimensions in millimetres).

\section{RESULTS AND DISCUSSION}

\section{Evaluation of Potential Cooling Available}

The potential heat absorption provided by the flow of LPG in the fuel system can be calculated by the specific enthalpy difference from the vapour phase to the liquid phase, multiplied by the mass flow rate. Curves plotted in Figure 3 shows the cooling power theoretically available if the LPG flow rate is completely evaporated in an adiabatic device without superheating. Values are plotted at three different pressure levels against the load of a $1998 \mathrm{~cm}^{3}$ SI engine tested by the present authors [3].

Looking at the graph curves in Figure 3, the lower the evaporation pressure, the lower the maximum engine power (and the maximum cooling thermal power theoretically achievable) because of the inability to obtain high gaseous LPG flow rates at low evaporation pressure. The solid marker plotted in the graph shows the design operating condition of the test rig. In particular, it is assumed that the maximum LPG mass flow rate of $6 \mathrm{~g} / \mathrm{s}$ and the evaporator outlet-to-inlet enthalpy change is $298.6 \mathrm{~kJ} \mathrm{~kg}^{-1}$ and there is no change in the composition of LPG [32]. So, the associated cooling power is 1.79 $\mathrm{kW}$. Assuming that the air enters the evaporator at $38{ }^{\circ} \mathrm{C}$ and $90 \%$ relative humidity $(\mathrm{RH})$, i.e. at $143 \mathrm{~kJ} \mathrm{~kg}^{-1}$ specific enthalpy level, and leaves the evaporator at $15{ }^{\circ} \mathrm{C}$ and $50 \% \mathrm{RH}$, i.e. at $29 \mathrm{~kJ} \mathrm{~kg}^{-1}$ specific enthalpy level, the specific enthalpy drop within the airflow results equal to $114 \mathrm{~kJ} \mathrm{~kg}^{-1}$. Therefore, according to this preliminary estimate, the 
maximum airflow rate required for the blower is $1.79 \mathrm{~kW} / 114 \mathrm{~kJ} / \mathrm{kg}=15.7 \mathrm{~g} / \mathrm{s}$. The $2 \mathrm{~A} / 3600 \mathrm{rpm}$ electric blower included in the test rig is able to deliver an airflow rate at the evaporator outlet equal to $16 \mathrm{~g} / \mathrm{s}$. Hence, the airflow rate could be able to provide the necessary heat to completely evaporate also the highest LPG flow rate considered during the test. However, the actual thermodynamic state of air and LPG at the evaporator outlet depends on the device geometry and performance.

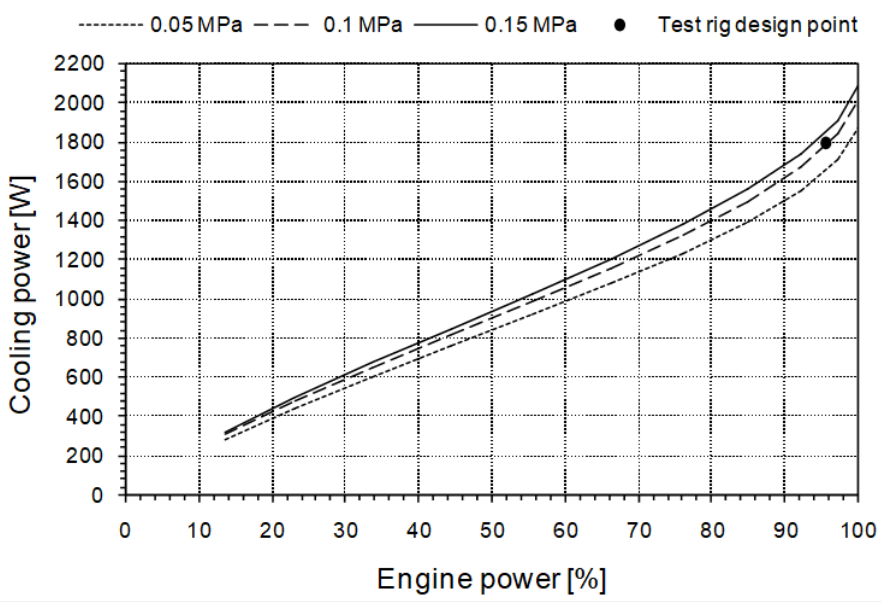

Figure 3. Evaluation of the cooling power from LPG evaporation.

\section{Cooling Power}

As the air passes across the evaporator, it becomes colder and drier because LPG evaporation absorbs heat from the airflow and some moisture in the air condenses. Therefore, the actual cooling power $\dot{q}_{e v}$ can be calculated by Eq. (1) in which $\dot{m}_{a}$ is the air mass flow rate and $\Delta h$ is the specific enthalpy drop within the air stream that crosses the evaporator. Values of air specific enthalpy $(h)$ can be calculated as a function of the temperature and humidity data.

$$
\dot{q}_{e v}=\dot{m}_{a} \cdot \Delta h
$$

The time history of air temperature and relative humidity $(\mathrm{RH})$ at the evaporator outlet recorded during the tests for a $0.15 \mathrm{MPa}$ gauge evaporation pressure are presented in Figure 4. The resulting cooling power at various LPG flow rates is presented in Figure 5. Figure 4(a) shows that the greater the flow rate of LPG the higher the thermal energy required by evaporation. As a result, the cooling power increases as shown in Figure 5. The concurrent cooling and pressure decreasing of the air stream lead to the drop in the humidity level shown in Figure 4(b).

In Figure 6, steady-state data of cooling power shown in Figure 5 are compared to cooling powers calculated for an evaporation pressure of $0.15 \mathrm{MPa}$, assuming that LPG completes the evaporation without superheating (solid line plotted in Figure4). Discrepancies at both low and high LPG flow rates are clearly visible. Experimental data at low flow rates are higher than the calculated one due to LPG superheating. On the other hand, at high flow rates, experimental data are lower than theoretical values because LPG evaporation is incomplete. Indeed, during the test, high fuel flow rates could not be fully 
evaporated (the liquid phase is clearly visible in Figure 7) because the heat exchanger area is not sufficient.

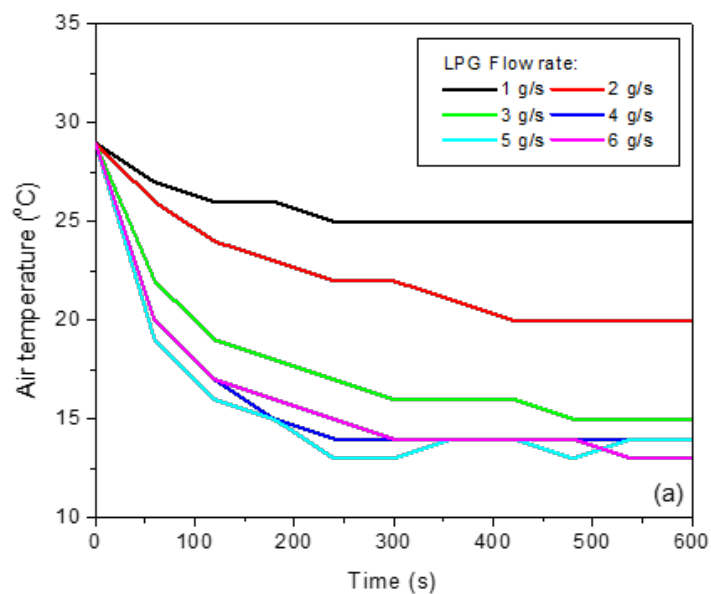

(a)

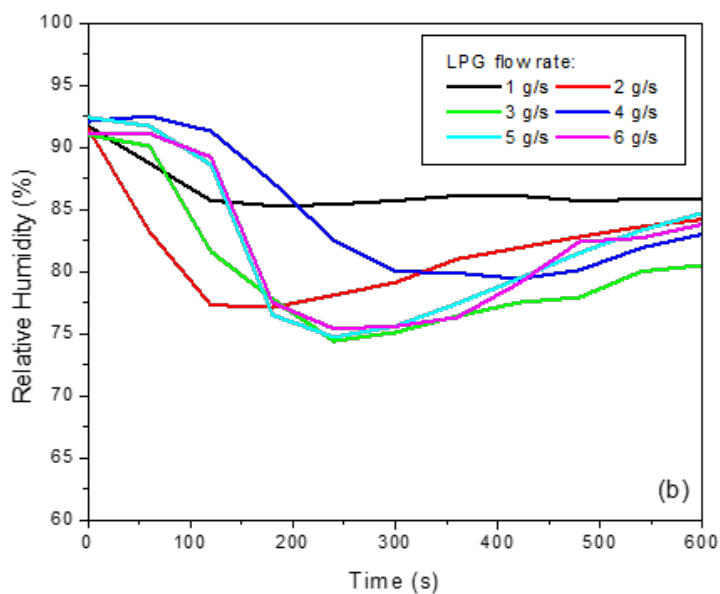

(b)

Figure 4. Measured air temperature (a) and the RH (b) at the evaporator outlet.

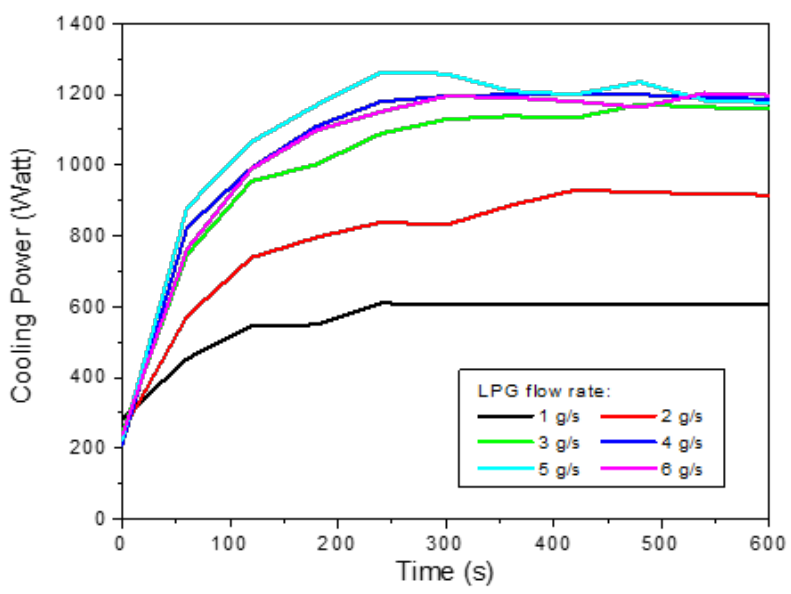

Figure 5. Measured cooling power (LPG evaporation pressure equal to $0.15 \mathrm{MPa}$ ).

In addition, an iced layer rapidly grew on the evaporator fins during the transient operation of the system. This layer limited the air-LPG heat exchange once the steadystate condition was achieved because it acted as thermal insulator and blockage to the airflow. The ice formation layer starts from the inlet evaporator and then it expands towards $x$ and $y$ as shown in Figure 7(b). At flow rate above $3 \mathrm{~g} / \mathrm{s}$, this ice formation layer immediately fills the entire surface of the evaporator wall. As a consequence, airflow was cooled from $29^{\circ} \mathrm{C}$ to only $13^{\circ} \mathrm{C}$ (instead of $8^{\circ} \mathrm{C}$ ) with a humidity reduction of $7 \%$ (instead of $41 \%$ ). The actual cooling power absorbed by the airflow equals $925 \mathrm{~W}$. The remaining heating power needed to complete the LPG evaporation (about $275 \mathrm{~W}$ ) is provided by the ambient, being the LPG ducts between the evaporator and the two measuring sections (number 2 and 3 in Figure3) not perfectly insulated. 




Figure 6. Calculated and measured cooling power due to LPG evaporation at $0.15 \mathrm{MPa}$.

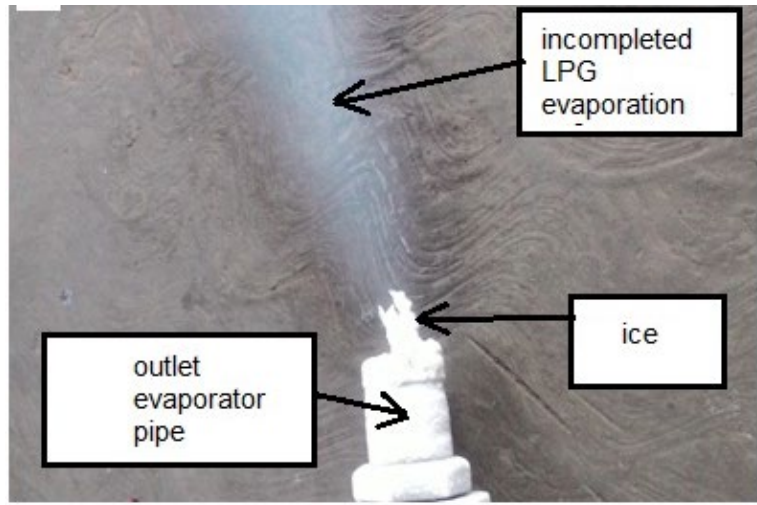

(a)

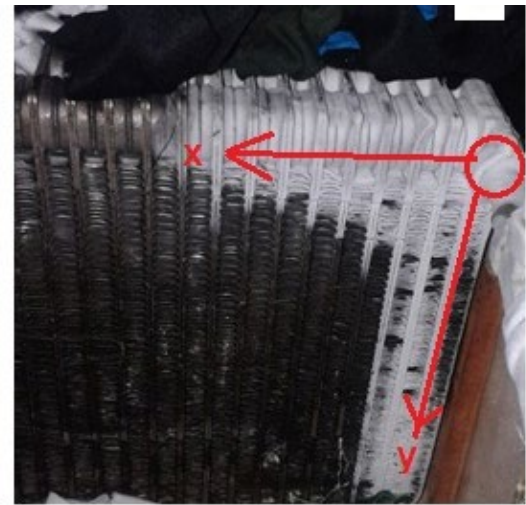

(b)

Figure 7. Incomplete LPG evaporation due to the limitation of the heat transfer area in the evaporator (a) and ice formation layer formed in the evaporation wall (b).

\section{Energy Efficiency Ratio (EER)}

The coefficient of performance (COP) usually introduced to weight the quality level of reverse thermodynamic cycles (see, e.g., Shah \& Gupta [33] for an LPG refrigeration cycle study) is not easy to calculate in the present case. At least, an estimation of the power absorbed from the LPG pumping station should be performed in order to compare the energy performance of LPG-evaporation conditioning systems respect to the performance of standard air conditioning systems for automotive applications. On the other hand, although the advantages of LPG evaporation for vehicles cabin cooling are questionable in terms of actual global energy saving, the economic advantage of air conditioning based on LPG evaporation is clear. Accordingly, the performance of LPGevaporation air conditioning systems can be effectively calculated by the EER [34]. EER is defined as the ratio of cooling power produced by the LPG evaporation $\left(\dot{q}_{e v}\right)$ to the total power input needed to produce the cooling power (from Eq. (2) and Figure 8). Note that in LPG-evaporation conditioning ( $1 / 2$ cycle $\mathrm{AC}$ system, without compressing and condensing stage), the power input is limited to the electric power required to drive the blower $\left(w_{b}\right)$, whereas, in conventional air conditioning systems, the power input is 
significantly higher, because both the refrigerant fluid compressor and the fan condenser must be supplied.

$$
E E R=\frac{q_{e v}}{w_{b}}
$$

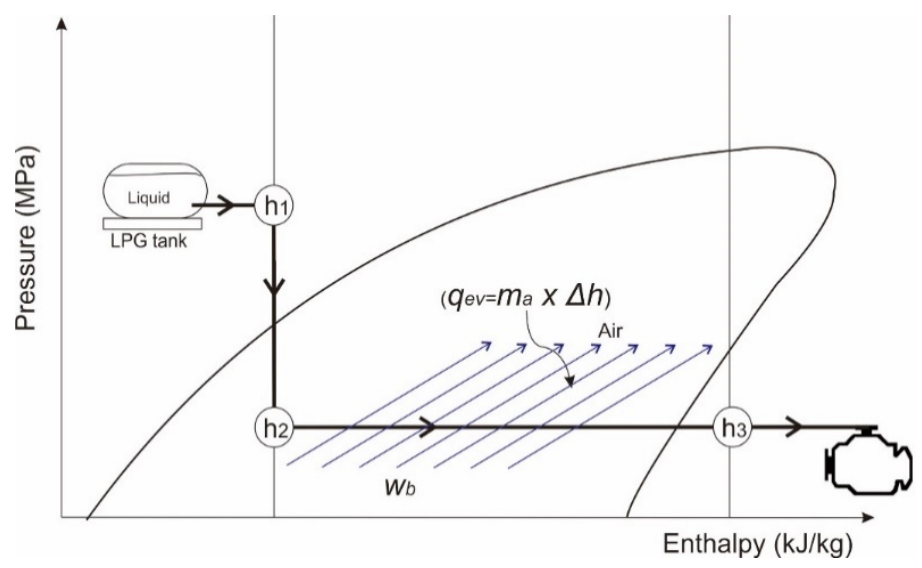

Figure 8. Diagram of LPG thermodynamic processes for EER calculation.

EER values can be calculated from the steady-state cooling powers plotted in Figure 5, considering that the maximum power associated to LPG evaporation (about 1.2 $\mathrm{kW}$ ) can be easily transferred to the airflow once the actual evaporator is replaced by a larger device. Known the electric consumption of the blower included in the test rig (440 W), the EER values can be computed. Results are presented in Figure 9.

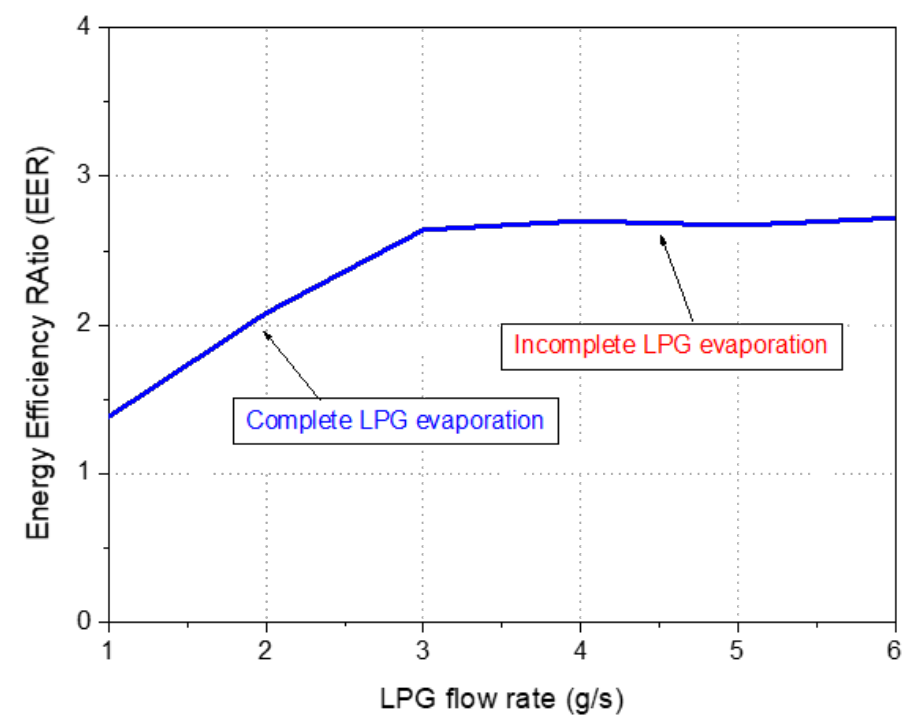

Figure 9. EER of the LPG-evaporation conditioning prototype ( $1 / 2$ cycle AC system) at an evaporation pressure of $0.15 \mathrm{MPa}$.

Testing on this lab-scale prototype, we found there was a cooling power of 1.2 $\mathrm{kW}$ at $3 \mathrm{~g} / \mathrm{s} \mathrm{LPG}$ flow rates. Assuming a passenger vehicle has a cooling load of $7 \mathrm{~kW}$ [20], the developed AC system is capable of contributing around $17 \%$ of the total cooling load. Greater cooling power can be harvested (around $2.7 \mathrm{~kW}$, at a mass flow rate of 6 
g/s LPG), if the heat exchange from LPG to air is not disturbed by ice formation on the evaporator wall. In addition, the total fuel efficiency has also been shown to increase by more than $3 \%$, as explained in previous studies [35].

\section{CONCLUSION}

A prototype of a novel air conditioning system for LPG-fuelled vehicles $(1 / 2$ cycle AC system) is tested at an evaporation pressure of $0.15 \mathrm{MPa}$. This pressure allows the superheating of LPG flow rates ranging from 1 to $4 \mathrm{~g} / \mathrm{s}$ and the partial evaporation of flow rates ranging from 4 to $6 \mathrm{~g} / \mathrm{s}$. When the LPG flow rate exceeds $3 \mathrm{~g} / \mathrm{s}$, the cooling power provided by the LPG evaporation remains fairly constant and equal to about $1.2 \mathrm{~kW}$, due to poor heat exchange area and ice formation on the evaporator fins that increase the thermal resistance. The design of a specific evaporator may allow achieving higher cooling powers (also above $1.79 \mathrm{~kW}$, considering the LPG superheating) with the only electric consumption of the fan (usually less than $0.5 \mathrm{~kW}$ ). The EER related to $1.2 \mathrm{~kW}$ of cooling power ranges between 1.2 and 2.7 when the LPG flow rate is increased from 1 to $6 \mathrm{~g} / \mathrm{s}$, respectively. The analysed system may contribute to the fuel economy of light-duty vehicles, considering that the maximum cooling load needed by a car typically achieves 3.5-7 kW. In case of low or null cooling load, the complete LPG evaporation must be achieved in the standard kit for LPG gas injection, which should be managed by an additional control system.

\section{ACKNOWLEDGEMENT}

This research was supported by Automotive Laboratory of Universitas Muhammadiyah Magelang for test facilities and apparatus.

\section{REFERENCES}

[1] Werpy MR, Burnham A, Bertram K. Propane vehicles : Status, challenges, and opportunities. Argonne, 2010.

[2] ETSAP. Automotive LPG and Natural Gas Engines. (C) IEA ETSAP - Technology Brief T03 2010; 1-5.

[3] Masi M, Gobbato P. Measure of the volumetric efficiency and evaporator device performance for a liquefied petroleum gas spark ignition engine. Energy Conversion and Management 2012; 60: 18-27.

[4] Ceviz MA, Yüksel F. Cyclic variations on LPG and gasoline-fuelled lean burn SI engine. Renewable Energy 2006; 31: 1950-1960.

[5] Campbell M, Wyszyński ŁP, Stone R. Combustion of LPG in a spark-ignition engine. SAE Technical Paper: 2004-01-09; 2004.

[6] Manzie C, Watson H, Marimuthu Palaniswami. Air fuel ratio control in liquefied petroleum gas injected SI engines. In: 15th Triennial World Congress. Barcelona: IFAC, 2002.

[7] Ceviz MA, Kaleli A, Güner E. Controlling LPG temperature for SI engine applications. Applied Thermal Engineering 2015; 82: 298-305.

[8] Çinar C, Şahin F, Can Ö, et al. A comparison of performance and exhaust emissions with different valve lift profiles between gasoline and LPG fuels in a SI engine. Applied Thermal Engineering 2016; 107: 1261-1268.

[9] World LPG Association. Autogas incentive policies. Neuilly-sur-Seine, 2016. 
[10] Kim J, Choi K, Myung CL, et al. Experimental evaluation of engine control strategy on the time resolved THC and nano-particle emission characteristics of liquid phase LPG direct injection (LPG-DI) engine during the cold start. Fuel Processing Technology 2013; 106: 166-173.

[11] Kim K, Kim J, Oh S, et al. Lower particulate matter emissions with a stoichiometric LPG direct injection engine. Fuel 2017; 187: 197-210.

[12] Myung CL, Ko A, Lim Y, et al. Mobile source air toxic emissions from direct injection spark ignition gasoline and LPG passenger car under various in-use vehicle driving modes in Korea. Fuel Processing Technology 2014; 119: 19-31.

[13] Kim TY, Park C, Oh S, et al. The effects of stratified lean combustion and exhaust gas recirculation on combustion and emission characteristics of an LPG direct injection engine. Energy 2016; 115: 386-396.

[14] Kim K, Kim J, Oh S, et al. Evaluation of injection and ignition schemes for the ultra-lean combustion direct-injection LPG engine to control particulate emissions. Applied Energy 2017; 194: 123-135.

[15] Suyabodha A. Comparison the Rate of Energy Consumption between Gasoline95 and LPG in Spark Ignition Engine under Real Driving Conditions. Energy Procedia 2017; 118: 164-171.

[16] Norris J. Light Goods Vehicle - CO2 Emissions Study. Didcot, Oxfordshire, 2010.

[17] Edwards R, Mahieu V, Griesemann JC, Larivé JF, Rickeard DJ. Well-to-wheels analysis of future automotive fuels and powertrains in the european context. SAE Technical Papers. 2004;(724):1-13.

[18] Price P, Guo S, Hirschmann M. Performance of an evaporator for a LPG powered vehicle. Applied Thermal Engineering 2004; 24: 1179-1194.

[19] Setiyo M, Soeparman S, Hamidi N, et al. Cooling effect characteristics of a $1 / 2$ cycle refrigeration system on an LPG fuel system. International Journal of Refrigeration 2017; 82: 227-237.

[20] Farrington R, Rugh J. Impact of Vehicle Air-Conditioning on Fuel Economy, Tailpipe Emissions, and Electric Vehicle Range. In: Earth Technologies Forum, Washington, D.C.; 31 October, 2000.

[21] Benouali J, Clodic D, Mola S, et al. Fuel consumption of mobile air conditioning method of testing and results. In: The Earth Technology Forum. Washington, pp. $1-10 ; 2003$.

[22] Bharathan D, Chaney L, Farrington RB, et al. An overview of vehicle test and analysis results from NREL's A/C fuel use reduction research. In: VTMS 8 Vehicle Thermal Management Systems Conference and Exhibition. Nottingham, England: National Renewable Energy Laboratory, 2007, pp. 567-580.

[23] Huff S, West B, Thomas J. Effects of Air Conditioner Use on Real-World Fuel Economy. SAE Technical Paper: 2013-1-5; 2013.

[24] Lee J, Kim J, Park J, et al. Effect of the air-conditioning system on the fuel economy in a gasoline engine vehicle. Proceedings of the Institution of Mechanical Engineers, Part D: Journal of Automobile Engineering 2013; 227: 66-77.

[25] Rugh J, Hovland V, Andersen S. Significant fuel savings and emission reductions by improving vehicle air conditioning. In: 15th Annual Earth Technologies Forum and Mobile Air Conditioning Summit. Washington D.C, USA: National Renewable Energy Laboratory, 2004.

[26] Johnson VH. Fuel used for vehicle air conditioning: A state-by-state thermal comfort-based approach. Society of Automotive Engineers, Inc 2002; 01: 19571970 . 
[27] Alsaad MA, Hammad MA. The application of propane/butane mixture for domestic refrigerators. Applied Thermal Engineering 1998; 18: 911-918.

[28] Palm B. Hydrocarbons as refrigerants in small heat pump and refrigeration systems - A review. International Journal of Refrigeration 2008; 31: 552-563.

[29] Calm JM. The next generation of refrigerants - Historical review, considerations, and outlook. International Journal of Refrigeration 2008; 31: 1123-1133.

[30] Dalkilic AS, Wongwises S. A performance comparison of vapour-compression refrigeration system using various alternative refrigerants. International Communications in Heat and Mass Transfer 2010; 37: 1340-1349.

[31] El-Morsi M. Energy and exergy analysis of LPG (liquefied petroleum gas) as a drop in replacement for R134a in domestic refrigerators. Energy 2015; 86: 344353.

[32] Setiyo M, Syaka D, Waluyo B, et al. Cooling effect potential from liquefied petroleum gas flow in the fuel line of vehicle. International Journal of Automotive and Mechanical Engineering 2017; 14: 2229-8649.

[33] Shah IH, Gupta K. Design of LPG refrigeration system and comparative energy analysis with domestic refrigerator. International Journal of Engineering Sciences \& Research Technology 2014; 3: 206-213.

[34] Wang SK. Handbook of air conditioning and refrigeration. 2nd Editio. New York: The McGraw-Hill Companies, Inc, 2000.

[35] Setiyo M, Waluyo B. Fuel as secondary refrigerant on LPG fuelled vehicle: A thermodynamics analysis. Journal of Mechanical Engineering and Sciences 2019; 13: $4390-4402$. 